\title{
The Assessment of the Amount of Soil Material Deposited on the Bottom of a Dry Erosive-Denudation Valley
}

\author{
Andrzej Mazur ${ }^{* *}$, Radomir Obroślak ${ }^{1}$ Kamil Nieścioruk ${ }^{1}$ \\ 1 University of Life Sciences in Lublin, Department of Environmental Engineering and Geodesy, \\ ul. Leszczyńskiego 7, 20-069 Lublin, Poland \\ * Corresponding author's e-mail: amazur70@op.pl
}

\begin{abstract}
The work presents the results of research on erosion and landform changes of a bottom of a dry erosive-accumulation valley in Elizówka in 1958, 1970 and 2016. The changes have been examined with the use of geodetic topographic surveys techniques. The research field was a 480 -metres long part of the valley bottom. The topographic surveys in 1958 and 1970 were conducted with longitudinal (parallel to the bottom of the valley) and cross (every 20 metres) sections method. In 2016 the modern measuring devices were used. All the results, together with coordinates of points and historical data were converted into GIS spatial layer. The altitude values formed the input data for interpolation of rasters showing changes of the topography in three periods. Three TIN models were also developed to distinguish erosion and accumulation zones plus the quantity of eroded and accumulated material. The valley on the majority of its length has been raised and has changed from V-shaped into U-shaped. Accumulation of the soil material led to levelling the bottom. Accumulation concentrates along a flow line, while soil washout mainly at the bottom of slopes. The thickest sediment layers were observed in the lowest part. For the whole 1958-2016 period a total of $3470 \mathrm{~m}^{3}$ soil material has been deposited on the area of about 1.62 ha, while in the same time only $130 \mathrm{~m}^{3}$ has been eroded (from $0.22 \mathrm{ha}$ ).
\end{abstract}

Keywords: water erosion, valley bottom, soil material accumulation, geodetic techniques

\section{INTRODUCTION}

Both land relief and soil are under constant pressure from natural and anthropogenic factors that initiate numerous - often adverse - changes in the soil environment. The soil plays an important utilitarian, ecologic and culture roles [Kowalik 2001] and its quality in the natural environment is defined by resistance to degradation and ability to regenerate [Seybold et al. 1999]. The most soil and relief destructive factor in a world scale is an intensive water erosion. It reshapes landforms and changes soil profiles (reaching even deeper layers in case of the gully erosion) [Daniels et al 1985; Jankauskas, Fullen 2002; Mazur et al. 2016; Young, Hammer 2000], washes out nutrients of plants and differentiates physical and chemical soil characteristics [Hladký et al. 2016; Ijaz et al. 2006; Licznar et al. 1998] and, as an effect, lowers soil productivity [Arriaga, Lowery 2003; Duan et al. 2011]. Improperly used soil may be easily degraded with erosion [Olson et al. 2002]. Regeneration to its initial state is very difficult or even impossible as soil-forming processes are very slow [Pimentel et al. 1993]. This is why the soil is classified as a hardly renewable natural resource. Thus, research on water erosion scale and range is not of cognitive character only, but has also a very utilitarian aspect - it is an important element of implementation of sustainable erosive soil usage, leading to optimization of crops with minimizing the extent of degradation processes.

Bottoms of dry erosive-accumulation valleys are classified as easily reshaped by the water erosion with both washout and accumulation [Mazur 2005]. Quantitative monitoring of these processes forms a serious challenge. The most popular method was analysing changes on longitudinal 
and cross sections [Grzywna, Pałys 2000]. The research of that kind was also conducted on slopes and atop [Pałys, Mazur 1998]. This method was very time- and labour-consuming however. Recently, a technological advance in digital surveying devices changed the situation. Such devices are widely used in engineering as well as environmental tasks, including these erosion-related [Alba et al. 2006; Kociuba et al. 2014; Lim, Suter 2009; Obroślak et al. 2017; Richardson et al. 2014]. They provide fast and precise measurements, fastening and facilitating quantitative monitoring of natural processes.

The work presents the results of research on erosion and landform changes of a bottom of a dry erosive-accumulation valley in Elizówka in 1958, 1970 and 2016. The changes have been examined with the use of geodetic topographic surveys techniques.

\section{MATERIALS AND METHODS}

The research object is located in Elizówka - a village on the Lublin Upland, in the eastern part of the Nałęczów Plateau mesoregion [Kondracki 1994], near the northern boundary of Lublin(fig. 1). Landforms are typical for the Lublin Upland here, with vulnerable to erosion soils on deep loess. On tops retisols are dominant, on slopes - soils eroded to different extent and on bottoms - deluvial soils with thick humus horizon [Turski et al. 1992]. Mean annual precipitation for the region is about $550 \mathrm{~mm}$. The surface runoff is most significant during the spring snow melting and during the spring-summer storm rainfalls [Mazur 2005].

The research field was a 480-metres long part of the valley bottom, oriented north-south (fig. 2). The width of the bottom differs from 10 to 53 metres. The western exposure slope is $150 \mathrm{~m}$ in length on average and is slightly upwardly convex with many troughs and young tributary valleys. The eastern exposure slope is $80 \mathrm{~m}$ in length and has convex-concave profile. The bottom and both slopes of the valley form a part of one croprotation ploughed field. Its slope-wise cultivation increases erosion.

The topographic surveys in 1958 were conducted with longitudinal and cross sections method in a local coordinate system using ranging rods, double pentaprism, measuring tapes and levelling set (optical level PZO Ni4 with a set of wooden level staffs). The longitudinal section was lined up parallel to the bottom of the valley and bench marked. The cross sections were done every 20 metres each. The surveys of 1970 were conducted using the same method and devices. In 2016 the modern measuring devices were used. The first step was to re-measure XYH coordinates of 1956 section bench marks. $X$ and $Y$ coordinates in the PL-2000 (zone 8) Polish reference system were obtained with GNSS-RTK technique

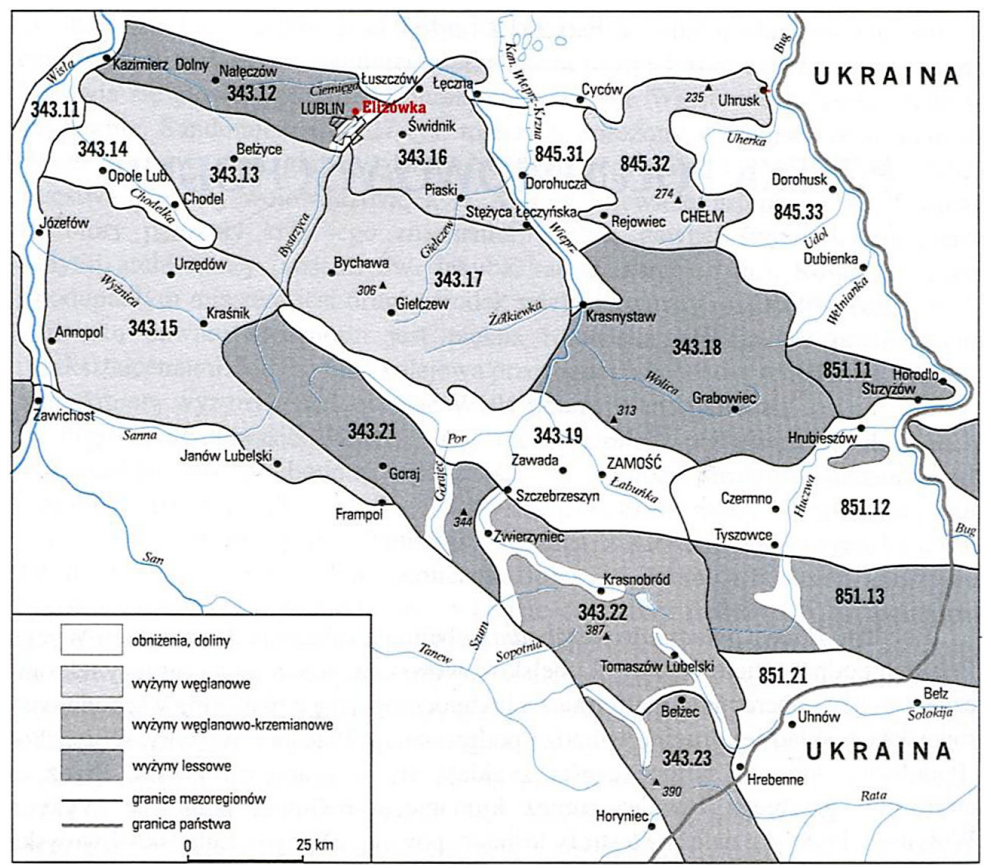

Fig. 1. Location of the research object on the Lublin Upland regions (343.12 - mesoregion of the Nałęczów Plateau) 


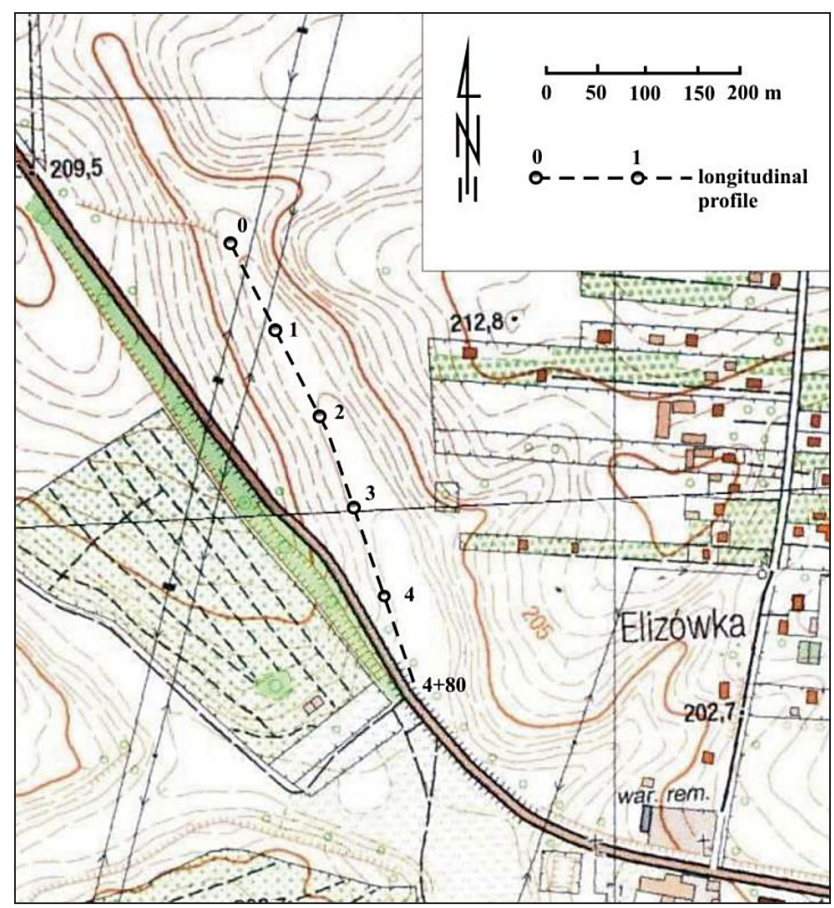

Fig. 2. The longitudinal section profile and the research erosive-accumulation valley

and TPINETpro corrections using Topcon HiPer $\mathrm{V}$ receiver with FC 2600 controller. Altitudes $(\mathrm{H})$ in the Kronstadt 86 reference system were measured with Leica Sprinter 150M digital level plus a set of levelling staffs using $3^{\text {rd }}$ class national control network.

The WinKalk software was used to calculate the PL-2000 (zone 8) XY coordinates of 1958 and 1970 bench marks, originally in local, orthogonal reference system (they were obtained from original, archival measuring logs). The resulting data were loaded into Leica Viva CS15 controller. Measurements were done using Leica Nova MS 50 multistation which was centred on the section bench marks and aimed on the next point. Leica Viva was mounted on rod with $360^{\circ}$ prism. After each point was set out, its altitude was measured. The results (exported from the controller), together with coordinates of points as well as historical data were converted into discrete vector spatial layer in PL-2000 (zone 8) coordinate system using ArcGIS programme. The altitude values of points formed the input data for interpolation. Natural neighbour algorithm was used to create three raster datasets (with spatial resolution of $20 \mathrm{~cm}$ ) showing changes of the valley's bottom topography between 1958 and 1978, 1978 and 2016 plus 1958 and 2016. Spatial extents of rasters were limited to outermost measuring points. Three TIN models were also developed. Using surface difference tool, the volume and the area of changes were detected for three mentioned periods hence it was possible to distinguish erosion and accumulation zones as well as the quantity of eroded and accumulated material.

The next step was to create longitudinal profile and to calculate the changes of a grade-line of the bottom.

Table 1. Areas of changes and volumes of soil material transported in the bottom of the analysed valley

\begin{tabular}{|c|c|c|c|c|c|}
\hline \multirow{2}{*}{ Period } & \multicolumn{2}{|c|}{$\begin{array}{c}\text { Area of } \\
{\left[\mathrm{m}^{2}\right]}\end{array}$} & \multicolumn{2}{c|}{ Volume of soil material $\left[\mathrm{m}^{3}\right]$} & \multirow{2}{*}{$\begin{array}{c}\text { Soil material } \\
\text { balance }\left[\mathrm{m}^{3}\right]\end{array}$} \\
\cline { 2 - 6 } & sediment & denudation & deposited & eroded & 3340 \\
\hline $1958-2016$ & 16157 & 2222 & 3470 & 130 & 1445 \\
\hline $1978-2016$ & 14662 & 3717 & 1595 & 150 & 1895 \\
\hline $1958-1978$ & 16531 & 1848 & 1998 & 103 & \multirow{2}{*}{} \\
\hline
\end{tabular}




\section{RESULTS}

Changes that occur along longitudinal section of bottoms of valleys are important for landforms evolution as the bottom is the erosion base for slopes. Water erosion on slopes increases with the lowering of the bottom, leading to heavy soil degradation. Analyse of measurements of the erosive-accumulation valley's flow line altitude in 1958, 1978 and 2016 (fig. 3) justify conclusions on erosive processes that occur and reshape the relief of the valley. The valley on the majority of its length has been raised. The longitudinal sections reveal the biggest increase happened on $80 \mathrm{~m}$ part from hectometre $0+00$ to $0+80$ and on $60 \mathrm{~m}$ from hectometre $4+20$ to $4+80$. The mean increase of the altitude observed for 1958-2016 period on these sections was $50 \mathrm{~cm}$ and $42 \mathrm{~cm}$ respectively (with maximum rise of $62 \mathrm{~cm}$ and $53 \mathrm{~cm}$ ). For 1978-2016 in turn, the increase was $18 \mathrm{~cm}$ and $24.5 \mathrm{~cm}$ (with maximum of $36 \mathrm{~cm}$ and $35 \mathrm{~cm}$ ) respectively. Lowering of the bottom was observed only on about 20 metres section around hectometre $1+40$. The change was up to $6 \mathrm{~cm}$ only however. For $1958-2016$ the mean increase in the bottom was about $31.3 \mathrm{~cm}$, what gives $0.54 \mathrm{~cm}$ per year. During 1978-2016 period the accumulation rate was almost half that value with total mean increase of $12.5 \mathrm{~cm}$ and annual $0.33 \mathrm{~cm}$. The highest rate of increase was observed for 1958-1978 period (total mean $18.8 \mathrm{~cm}$ and annual mean $0.94 \mathrm{~cm}$ ). The accumulated material, as cross sections show, changes the valley shape. It used to have a sharp-cut V-shaped bottom (especially in its upper section). It has been transformed into more gentle, U-shaped valley with time. Accumulation of the soil material led to levelling the bottom and lowering its longitudinal slope value which is about $1 \%$ now (with the highest rate of $2 \%$ in the upper section and $0.4 \%$ on the opposite side of the analysed valley.

The figure 4 shows raster of topography changes (visualised in $20 \mathrm{~cm}$ classes) for three periods: 1958-1978, 1978-2016 and 1958-2016. They prove both accumulation and washout occur in the analysed valley. Accumulation concentrates along a flow line, while soil washout mainly at the bottom of slopes, especially in the upper part of the research area. The thickest sediment layers (about 1 metre) for both 1958-2016 and 1978-2016 periods were observed in the lowest part of the bottom of the valley. This high
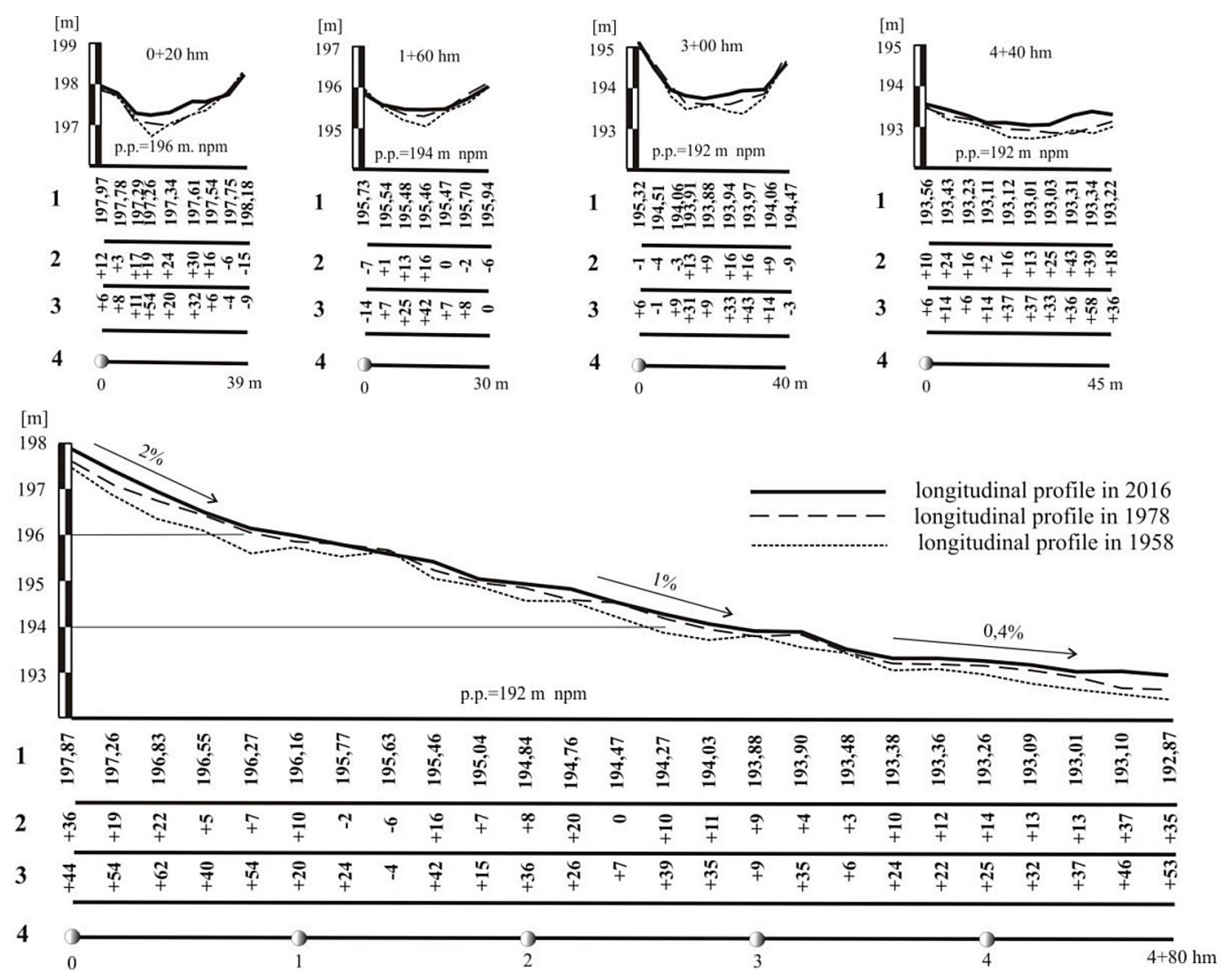

Fig. 3. Cross sections and longitudinal section. 1 - altitude of the bottom in 2016, 2 - increase (+) or decrease (-) of the altitude in 1978-2016 period, 3 - increase (+) or decrease (-) of the altitude in 1958-2016, 4 - hectometres 


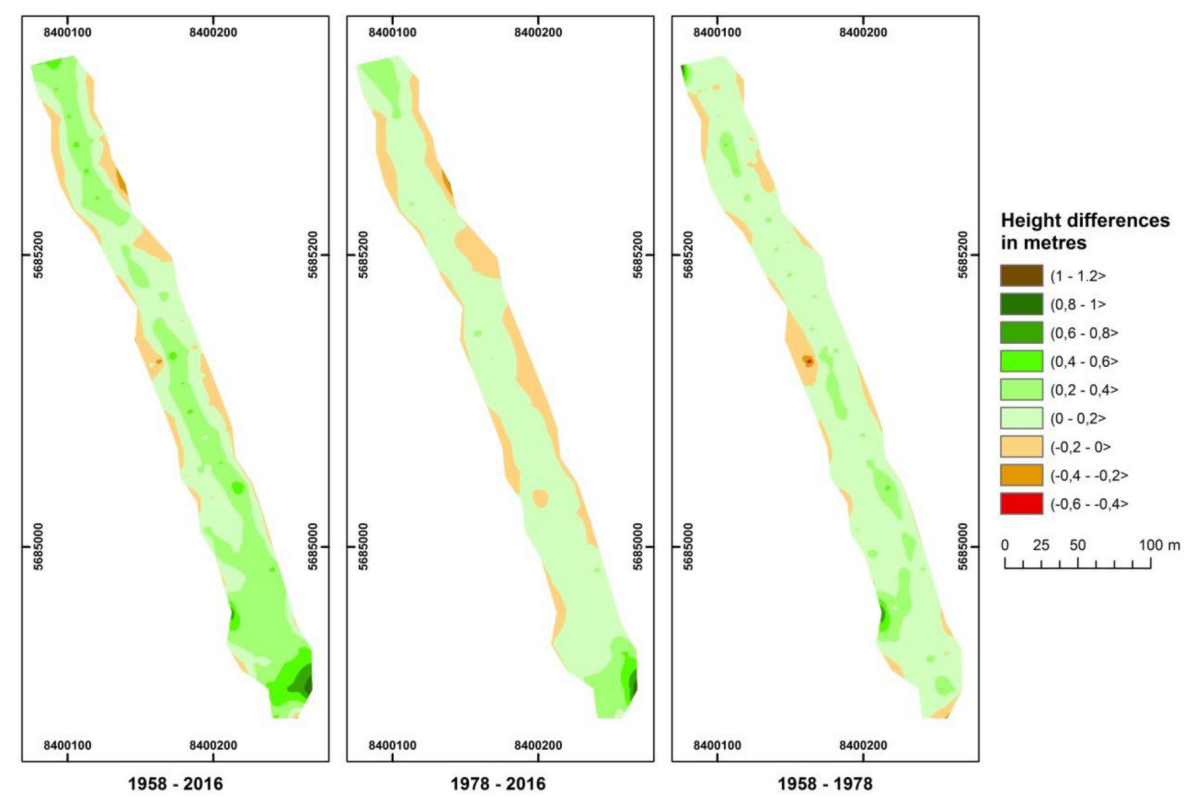

Fig. 4. Changes of topography for 1958-1978, 1978-2016 and 1958-2016 periods

accumulation of soil material is probably a result of partially blocked surface water runoff, as in the 1970s the valley has been dammed with 2-metres high earth bank with a road toward the village of Dys atop. To direct the surface water off the valley concrete culvert 2 by 1.35 metres has been built. However, the bottom of the culvert has been set above the valley's bottom. It still is about half a metre above the bottom of the valley, what makes a surface runoff difficult leading to temporary water stagnation and - as a consequence - sedimentation of soil material eroded from the upper part of the catchment of the analysed valley.

The topographic survey results were also used to create three TIN models. TIN (Triangulated Irregular Network) represents the surface in the vector data model by using sample points as vertices of triangles, which size and density corresponds with the complexity of the relief. Using surface difference tool, the volume and the area of changes were detected for the three periods hence it was possible to distinguish erosion and accumulation zones as well as volumes of each for all the three periods analysed. The results are shown in Table 1.

Looking at these results, it is evident than soil material accumulation processes are predominant over erosion in the bottom of the valley (on the 18379 square metres analysed). For the whole 1958-2016 period a total of 3470 $\mathrm{m}^{3}$ soil material has been deposited on the area of about $1.62 \mathrm{ha}$, while in the same time only $130 \mathrm{~m}^{3}$ has been eroded (from $0.22 \mathrm{ha}$ ). The balance is positive and the annual mean accumulation ratio is 57.6 cubic metres. During 1978-2016 the volume of the material accumulated on the bottom of the valley was 1595 $\mathrm{m}^{3}$, while eroded $-150 \mathrm{~m}^{3}$. The accumulation ratio was 38\% lower than for 1958-2016 period and was $38 \mathrm{~m}^{3}$ per year. For $1958-1978$ period the accumulation was $1895 \mathrm{~m}^{3}$ and erosion was $103 \mathrm{~m}^{3}$ with the annual ratio of $94.8 \mathrm{~m}^{3}$, higher by $65 \%$ in comparison with $1958-2016$ period and by $150 \%$ compared to this of 1978-2016.

One of reasons of decreasing accumulation ratio can be a change in the land use in the upper part of the catchment of the valley. Till the 1980s it was mainly agriculture usage with the domination of intensively eroded ploughed fields [Mazur 1972]. Since 1990 in Elizówka, neighbouring to the northern boundary of Lublin, many fields were turned into single-family house estates. The upper part of the catchment of the analysed area was no exception here. The increase of orchards and berries plantations has also been observed. Sodded interrows on plantations limited the water erosion intensity. It all undoubtedly led to smaller soil erosion and, consequently, lower amount of eroded soil material transported from the upper part of the catchment and deposited in the bottom of the valley. 


\section{CONCLUSIONS}

1. Water erosion plays an important role in relief changing processes of the erosive-accumulative valley. Erosion processes decrease gradient of a bottom of the valley and reshape the valley profile from $\mathrm{V}$ to $\mathrm{U}$-shaped form.

2. In the bottom part of the valley, near the flow line, accumulation of soil material prevails over its elusion.

3. During all the analysed periods the altitude of the bottom has increased as a result of soil material accumulation. Mean annual increase during 1958-2016 period was $0.54 \mathrm{~cm}$, with almost twice that much $(0.94 \mathrm{~cm}$ per year $)$ for 1958-1978 period. For 1978-2016 it was $0.33 \mathrm{~cm}$ per year.

4. Mean annual soil material accumulation in the bottom of the valley was $57.6 \mathrm{~m}^{3}$ during the longest period. For 1958-1978 it was about $65 \%$ faster, reaching $94.8 \mathrm{~m}^{3}$ per year and for 1978-2016 it was $38 \mathrm{~m}^{3}$ per year.

\section{Acknowledgments}

Publication supported by the Polish Ministry of Science and Higher Education as a part of the program of activities disseminating science from the project „Organization of the First International Science Conference - Ecological and Environmental Engineering", 26-29 June 2018, Kraków.

\section{REFERENCES}

1. Alba M., Giussani A., Roncoroni F., Scaioni M. Valgoi P. 2006. Geometric Modelling of a Large Dam Terrestrial Laser Scanning. In Proc. of FIG Mondial Congres, Germany, Oct. 8-13, pp. 15.

2. Arriaga F.J, Lowery B. 2003.Corn production on an eroded soil: effects of total rainfall and soil water storage. Soil and Tillage Research, 71, 87-93.

3. Daniels R.B., Gilliam J.W., Cassel D.K., Nelson L.A. 1985. Soil erosion class and landscape position in the North Carolina Piedmont. Soil Sci. Soc. Am. J., 499, 991-995.

4. Duan X., Xie Y., Ou T., Lu H. 2011. Effects of soil erosion on long-term soil productivity in the black soil region of northeastern China. Catena, 87, 268-275.

5. Grzywna A., Pałys S. 2000. Changes of topographic profile in dried valley bottom. Acta Agrophysica, $35,86-92$.
6. Hladký J., Novotná J., Elbl J., Kynický J., Juřička D., Novotná J., Brtnický M., 2016. Impacts of Water Erosion on Soil Physical Properties Acta Univ. Agric. Silvic. Mendelianae Brun., 64, 1523-1527.

7. Ijaz A., Khan F., Bhatti A.U. 2006. Some physicochemical properties of soil as influenced by surface erosion under different cropping systems on uplandsloping soil. Soil and Environ., 25(1), 28-34.

8. Jankauskas B, Fullen M.A. 2002. A pedological investigation of soil erosion severity on undulating land in Lithuania. Canadian Journal of Soil Sci., 82, 311-321.

9. Kociuba W., Kubisz W., Zagórski P. 2014. Use of terrestrial laser scanning (TLS) for monitoring and modelling of geomorphic processes and phenomena at a small and medium spatial scale in Polar environment (Scott River - Spitsbergen). Geomorphology 212, 84-96.

10. Kondracki J. 1994. Geografia Polski. Mezoregiony fizyczno-geograficzne. PWN W-wa, ss. 304.

11. Kowalik P. 2001. Ochrona środowiska glebowego. PWN, W-wa, ss. 258.

12. Licznar M., Licznar S.E., Zawerbny T. 1998. Wpływ erozji na niektóre właściwości fizykochemiczne gleb lessowych Dolnego Śląska. Bibliotheca Fragmenta Agronomica, 4A/98, 29-39.

13. Lim EH, Suter D. 2009. 3D terrestrial LIDAR classifications with super-voxels and multi-scale Conditional Random Fields. Computer-Aided Design, 41, 701-710.

14. Mazur A. 2005. Erozja gleb w rolniczej zlewni z okresowym odpływem wody na Wyżynie Lubelskiej w latach 1999-2003. Acta Agrophysica, 5(1), 85-92.

15. Mazur A. 2018. Quantity and Quality of Surface and Subsurface Runoff from an Eroded Loess Slope Used for Agricultural Purposes. Water, 10, 1132, doi:10.3390/w10091132

16. Mazur A., Obroślak R., Nieścioruk K., Król Ż., Gabryszuk J., Rybicki R. 2016. Analysis of erosion control constructions effectiveness the case of a road gully in Wielkopole (Lublin Upland) Journal of Ecological Engineering, 17, 4, 180-183.

17. Mazur Z. 1972. Zmiany rzeźby uprawnych zboczy lessowych w Elizówce. Annales UMCS, secctio E, vol. 27, 169-180.

18. Obroślak R., Mazur A., Jóźwiakowski K., Dorozhynskyy O., Grzywna A., Rybicki R., Nieścioruk K., Król Ż, Gabryszuk J., Gajewska M. 2017. Using terrestrial laser scanning in inventorying of a hybrid constructed wetland system. Water Science \& Technology, 76(9-10), 2664-2671.

19. OlsonK.R., Gennadiyew A.N.,Jones R.L., Chernyanskii S. 2002. Erosion pattern on cultivated and reforested hillslopes in Moscow Region, 
Russia. Soil Sci. Soc. Am. J., 66, 193-201.

20. Pałys S., Mazur A. 1998. Zmiany rzeźby na erodowanych lessach na terenie zabezpieczonym i kontrolnym. Bibliotheca Fragmenta Agronomica, 4A, 295-305.

21. Pimentel D., Allen J., Beers A., Guinand L., Hawkins A., Linder R., McLanghlin P. Meer B., Musonda D., Perdue D., Poisson S., Salazar R., Siebert S., Stoner K. 1993. Soil erosion and agricultural productivity. [w:] World soil erosion and conservation. Cambridge Univ. Press, Cambridge, 277-292.

22. Richardson J.J., Moskal L.M., Bakker J.D. 2014.
Terrestrial Laser Scanning for Vegetation Sampling. Sensors 14, 20304-20319.

23. Seybold C.A., Herrick J.E., Brejda J.J. 1999. Soil resilience: a fundamental component of soil quality. Soil Sci., 164, 224-234.

24. Turski R., Słowińska-Jurkiewicz A., Paluszek J. 1992. The effect of erosion on the spatial differentation of the physical prperties of Orthic Luvisols. Int. Agrophysics, 6, 123-136.

25. Young F.J., Hammer R.D. 2000. Soil-landform relationship on a loess-mantled landscape in Missouri. Soil Sci. Soc. Am. J., 61-4, 1443-1454. 